\title{
GENDER CHALLENGES FOR RURAL DEVELOPMENT POLICY
}

\author{
Nataliia KUTSMUS, Zhytomyr National Agroecological University, 7 Stary Blvd., Zhytomyr, 10008. Ukraine, kutsmusn@ukr.net \\ (corresponding author) \\ Oleksandr KOVALCHUK, Zhytomyr National Agroecological University, 7 Stary Blvd., Zhytomyr, 10008. Ukraine, \\ o.d.kovalchuk@gmail.com
}

\begin{abstract}
The article is devoted to the problem of gender inequality on rural areas and argued the necessity of forming gender sensitive rural development policy. Based on existing theories of institutionalism, the authors characterized gender as a social institute, forming the structure of rural society. The importance of gender equality for progressive rural growth of rural areas, effective use of women's human capital in development of rural communities is underlined. Methodological frameworks of research are formed on the basis of rural development, gender economy and institutional theories. Adopted methodological approach of United Nations Development Program to gender inequality index calculation is used for integrated evaluation the gender inequality in reproductive health, political empowerment, and economic activity on labor market in rural areas. Research results indicate permanent character of the gender inequality problem in rural society and it dependence from situation in rural economy system. Gender asymmetries in economic activity and educational attainment of rural population, it participation in political initiatives and decision-making, demographic processes caused the regional differentiation of gender inequality problem. Indicated gender problems are characterized as the challenges for growth of rural areas and should be taken into account in the process of forming rural development policy, transforming it from gender neutral to gender sensitive. Key points of such a policy are implementation of the gender mainstreaming concept in rural development policy; forming an inclusive model of rural economy development and social cohesion; diversification of rural labor market; stimulating transfer of knowledge and innovation.
\end{abstract}

Keywords: gender, gender equality, rural areas, rural development, policy.

\section{INTRODUCTION}

Gender relations in the system of rural economy are based on the well-established view of their content - they rely on the traditional for the rural society distribution of roles and responsibilities, power and resources between men and women. The latter are the driving force for the support and development of rural areas, both socio-culturally and economically. Rural women not only contribute to the preservation of traditions and rural lifestyles, they also form a significant proportion of the workforce in the rural economy and contribute to the development of rural areas in the face of permanent depopulation. Unfortunately, however, rural women are also an "invisible" driving force for rural development, whose economic importance is not properly reflected in statistics, and labor is often free of charge and does not guarantee material independence from other family members, and they do not acquire ownership to land and property.

Objective conditions in rural areas (unemployment, poverty, underdevelopment of transport networks and lack of basic services in education, health and care), while maintaining the traditional mentality that imposes stereotypical roles for women and men and restricting the first of them to a subordinate position in both private and public life, hindering the achievement of gender equality. This problem is compounded by the state's inability to adequately ensure gender mainstreaming in the development and implementation of legislative and policy measures related to agriculture and rural areas. However, formatting an effective rural development policy in a crisis of rural development objectively needs to take into account the gender parameters of the rural society, the features of the distribution of social roles, participation in production and business technologies, income opportunities and civic self-realization. In view of this, the purpose of the research is to identify and evaluate the depth of gender problems in the functioning of the rural economy and society, as well as to substantiate the main directions of their leveling in rural development policy. The object of the research is the process of gender relations in rural societies that take place in the economic, social and political spheres.

\section{RESEARCH METHODS}

The argumentation of theoretical provisions and conclusions of the research as for trends and patterns of gender principals rural development was designed on a systematic and interdisciplinary approach, based on scientific and applied researching of leading experts in rural development and conceptual foundations of gender economy and modern neoruralistic studies. In particular, the toolkit of institutionalism theories has made it possible to view the gender as a social institution, through which the structure of the rural society is formed (Martin, 2004; Thébaud, 2015). 
The conducted studies globally and nationally prove that a major barrier to the economic development of humanity is gender inequality, which is reflected in the asymmetry of women and men's access to power, education and employment, income, property, and inherent in each country, regardless of political constitution and the achieved level of development (Havnor, 2000; The Global..., 2018; Incorporating Equal..., 1996; Kossek et al., 2017; Lombardo et al., 2017). Gender inequality continues to be not only evidence of a social development low level in a particular country, a discriminatory indicator of the internal socio-cultural environment organization, but also a factor of economic oppression (Jayachandran, 2015; Kleven \& Landais, 2017; Sen, 1990), a kind of inhibitor of the progressive socio-economic transformations inherent in the global economy (Hankivsky, 2005; Kabeer, 2005; Okoń-Horodyńska, 2015; Wodon, 2018). In addition, a number of studies (Goverde et al., 2004; Majurin, 2010; Matysiak, 2015; McVay, 2013; Nemes \& Fazekas, 2002; Oedl-Wieser, 2015; Aufhauser et al., 2003; Shortall, 2015; Tavira \& Tapia, 2008) show that gender inequality is a constraint of the progressive rural development, and the gender-neutral rural development policies do not create opportunities for the full use of women's human capital.

The research methodology includes the following methods: terminological analysis and methods of formal logic when refining the categorical apparatus of gender research in the field of rural development; sociological survey - to determine the socio-economic, environmental and institutional features of rural development from the perspective of different sexes representatives. The sociological survey involved over 800 respondents living in rural areas and representing different gender, age and occupational groups, in proportion to the existing structure of the rural population; statistical and economic - to collect, process statistical data, study the dynamics of economic and social processes parameters in rural areas, estimate gender gaps and regional differentiation of gender disparity indicators by regional section; tabular and graphical visualization of the results. In particular, a methodological approach was used to calculate the Gender Inequality Index (GII) of the United Nations Development Program (Human development..., 2011; Permanyer, 2013), adapted to this study:

$$
G I I=1-4 \frac{\left[\left(\sqrt[3]{\left(\frac{1}{M M R} \times \frac{1}{A B R}\right)^{\frac{1}{2}}(F S P \times F P E R)^{\frac{1}{2}} L F P w}\right)^{-1}+\left(\sqrt[3]{(M S P \times M P E R)^{\frac{1}{2}} L F P m}\right)^{-1}\right]^{-1}}{\sqrt[3]{\left(\sqrt{\frac{1}{M M R} \times \frac{1}{A B R}}+1\right)(\sqrt{F S P \times F P E R}+\sqrt{M S P \times M P E R})(L F P w+L F P m)}}
$$

$M M R$ - maternal mortality ratio, per 100000 of births; $A B R$ - adolescent birth ratio, births per 1000 women under $19 ; F S P$ females share of seats in local authorities, \%; $M S P$ - males share of seats in local authorities, \%; FPMR - female population with at least secondary education, $\%$; $M P M R$ - male population with at least secondary education, $\%$; $L F P$ - female labour force participation rates, \%; $L F P m$ - female labour force participation rates, $\%$

The assessment of gender inequality in rural areas in the spheres of reproductive health, empowerment, and economic activity at the labor market was carried out using it.

\section{RESEARCH RESULTS}

Dynamic changes in the world economy and sharpening environmental contradictions of economic growth direct the process of forming of rural development policy model, capable to ensure an effective use of existing potential of rural areas and for counteracting the potential global risks, accordingly to the idea of sustainability. One of the basic components of sustainable development holistic concept is gender equality. Its attainment means gender determination and compliance of gender imperatives of development, in particular: ensuring equal and fair opportunities and the participation of men and women in forming of rural development policy; achieving gender symmetry in access to resources, profits, technologies, markets and services; equality of representation in management and opportunities for participation and leadership; integration of women into the process of promotion and use of innovation in rural economy.

However, institutional environment of rural development, parameters of gender relations in rural society, unfortunately, cause the existence of gender inequality. The calculation of the Gender Inequality Index for rural areas of Ukraine and analysis of changes in its values (Fig. 1) let to make the following conclusions:

1) process of overcoming the phenomenon of gender inequality in rural areas is not progressive, but the losses in human capital development caused by gender disproportions in different spheres life during the period of 20002016 decreased from 0.372 to 0.349 .

2) comparative analysis of the GII values for rural population and population of Ukraine as a whole, proves that existing institutional environment, especially informal institutions such as culture and customs, lifestyle, etc., helps to preserve the discriminatory socio-economic position of rural women, whereas this index is traditionally higher in rural areas;

3) prevalence of the level of economic activity of man compared to woman (makes the strong influence on existence of gender inequality (about $14 \%$ ). The reasons of gender gap in economic activity of rural population are mostly the following: first, the established social institutions approve the division of social and economic roles within the family favoring the paid employment outside the household (predominantly for men). Women as a rule realize necessary servicing functions in households; secondly, the roles of housewife and mother are invariably 
perceived as the most important for a woman's life program; third, the current principles of vertical and horizontal segregation for most professional groups outside the social and service sectors form the prerequisites for male employment.

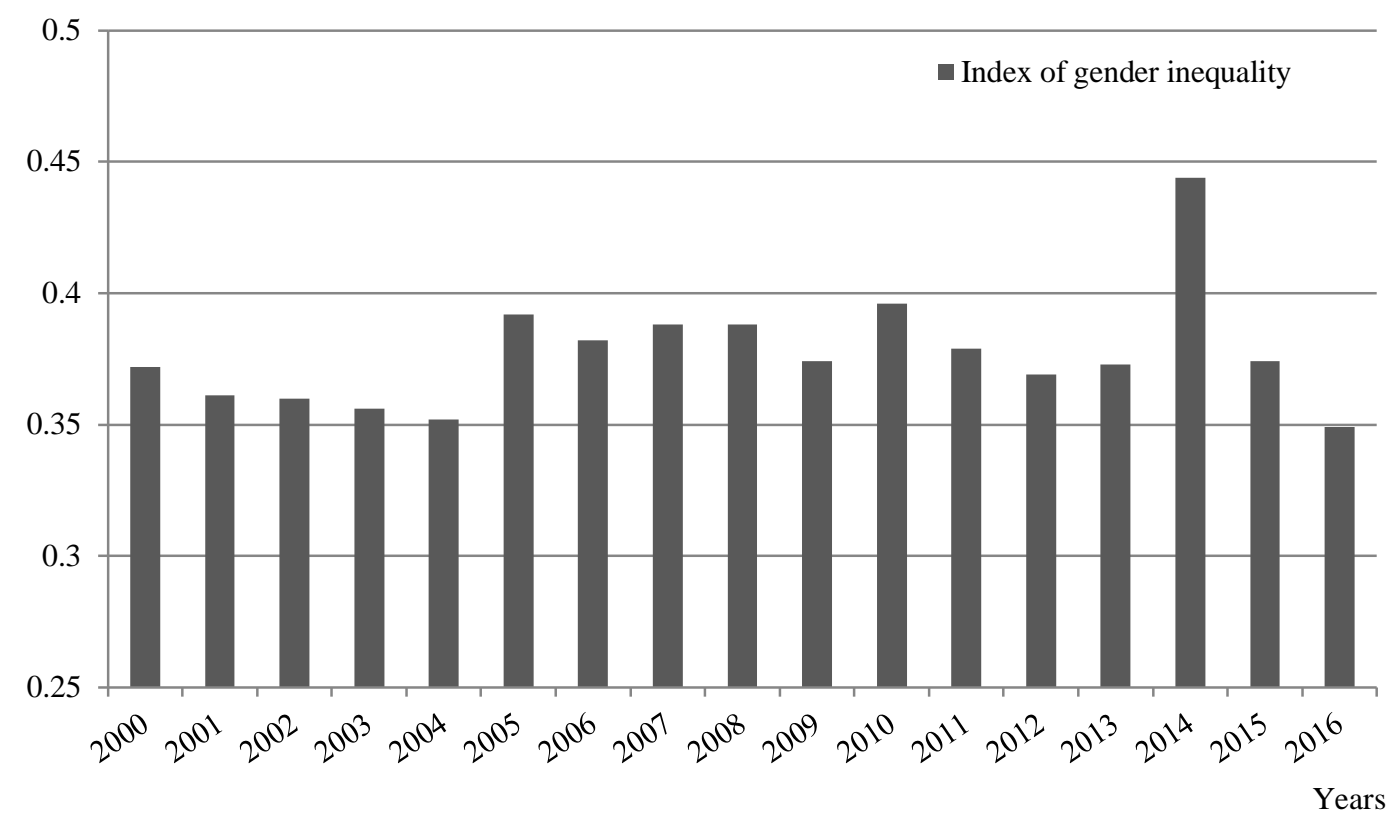

Figure 1. Dynamic of Gender Inequality Index for rural areas of Ukraine, 2000-2016

Consequently, gender differences, which take place in the socio-political area, are also observed in the rural economy. A key feature of gender asymmetry of rural economy is expansion of the spheres and enhancement of its manifestations as the hierarchy of this system grows. Gender-sensitive analysis of functioning of rural economy in Ukraine shows the existence of macro-, meso- and micro-level gender asymmetries: - gender gap in economic activity $(6.1 \%)$ and wages $(25.4 \%)$, educational potential of men and women; • vertical and horizontal segregation of labour; • disparity in the division of household responsibilities; • the exclusive role of women in reproductive labour. It confirms favourability of institutional environment for maintaining discriminatory frameworks at the level of rural society and in the field of business, policy formation and governance. At the same time, the gradual feminisation of local-government process at the level of rural communities and integration of women into agribusiness management systems indicate the initiation of positive changes in understanding of gender issues, rethinking of women's role in modern society and economy. In particular, there is a high level of women's involvement in local community governance processes - the share of female representatives among local government deputies in Ukraine is $56 \%$ and is below $50 \%$ only in the western regions of the country (Zakarpattja - $40 \%$, Lviv and Chernivtsi - $42 \%$, Ivano-Frankivsk regions - $43 \%$ ). This indicates increasing in the activity of their public-and-political position, as well as indicates the real opportunities for the formation and implementation of local gender-sensitive development policy in rural areas.

Regional differences in the formation and implementation of gender relations in rural economy led to the differentiation of Ukraine's regions by the value of gender inequality index, among which the leaders in providing parity opportunities for men and women are Lviv (0.206) and Zhytomyr (0.269) regions. The reason for such differences lies in the gender disparities that exist in the regions regarding to economic activity and educational attainment of rural population, it's participation in political initiatives and decision-making, and demographic processes. Thus, research of regional differences in the causes and depth of gender inequality in rural areas suggests that this problem remains relevant to all regions of Ukraine and demonstrates a close relationship with situation in rural economy. The evolutionary changes in rural society caused by the peasants' education and gradual digitization of lifestyles, the recognition of the need to integrate efforts for forming the models of collective solutions of local development problems, etc. have contributed to the political empowerment of rural women. However, even in such conditions, rural social and economic development policies remain gender-neutral character, not focused on addressing gender inequality and minimizing the loss caused by its existence. Overcoming of gender inequality requires progressive changes in the institutional environment of rural development, as well as destruction of stereotypes about the under-value of women as economic actors, redefining gender division of social roles in rural society, a modern version of which discriminates against women's economic opportunities. Gender mainstreaming - a concept that requires systematic inclusion of gender issues in activities of all public institutions and implementation of various policies - should be a tool to overcoming gender gaps in rural development.

\section{CONCLUSIONS AND DISCUSSION}

Thus, gender inequality, along with adverse demographic changes in rural areas and the progressive aging of the rural society, the jumble and unpredictability of economic transformations, the intensification of land use in the context 
of the global food crisis, the "ghostly" of social and economic equality, permanent social dynamics and institutional change, the redistribution of power and influence, shape the challenges of rural development. In view of this, gender should be seen as an integral part of the development and implementation of rural development strategies. Configurative changes in gender relations determine the nature of the evolution of rural society. It can be argued that there is a need for systematic improvement of national rural development policy, taking into account the existing inverse relationship between gender inequality and the well-being of rural populations.

The design of rural development policies, taking into account the social and economic challenges posed by the existence of gender inequality, is linked to the following areas:

1) implementation of the gender mainstreaming concept in rural development policy, which allows to ensure gender sensitivity of the implementation process of various policies and initiatives through the systematic inclusion of gender issues, priorities and needs of women and men in the activities of all public institutions, different types of policies to promote gender equality, mobilization of existing tools to achieve it;

2) application of an inclusive model of rural economy development, focused on the growth of material well-being of the rural population, as well as creating conditions for social cohesion and preservation of environmentally safe living. The priorities of this model are to reduce poverty through employment and improve the labor market. Given the economic aspect of gender inequality in rural areas, this is critically important, since maintaining a low level of diversification of the rural economy and narrowing the social sphere of the village increases the risk of further exclusion of women from the rural labor market, that is, further reducing their economic empowerment;

3) diversification of rural businesses, stimulated through economic and social motives. Expanding the types of rural business and the range of people integrated into it contributes to a new level of development of the sphere of application of work and personal professional self-realization, provides the development of economic opportunities for women, thereby enhancing their contribution to the development of the rural economy;

4) stimulating knowledge transfer and innovation. Guaranteeing gender inclusions, taking into account social consequences and strength of market linkages, a focus on leadership are key prerequisites for the effective process of the innovation development and, at the same time, the hallmarks of gender sensitivity. Along with this, gendersensitive rural development policy, focused on supporting the implementation of innovation in rural economic and social area, creates the preconditions for considering it as an innovation.

\section{REFERENCES}

1. Human Development Report. Sustainability and Equity: A Better Future for All. 2011. UNDP, New York.

2. Goverde H., Haan de H., Baylina M. 2004. Power and Gender in European Rural Development. Farnham, Ashgate.

3. Hankivsky O. 2005. Gender vs. Diversity Mainstreaming: A Preliminary Examination of the Role and Transformative Potential of Feminist Theory. Canadian Journal of Political Science Vol. 38, Iss. 4, pp. $977-1001$. https://doi.org/10.1017/S0008423905040783

4. Havnor A. 2000. Partnership, Political will and Agency - Gender mainstreaming at the EC level and in the central administration of Norway. Available at http://eucenter.wisc.edu/Conferences/Gender/havnoer.htm (accessed on 11/06/2013).

5. The world economic forum. 2018. The Global Gender Gap Report 2018. Available at http://www3.weforum.org/docs/WEF_GGGR_2018.pdf (accessed on 10/09/2019).

6. Commission of the European Communities. 1996. Incorporating Equal Opportunities for Women and Men into All Community Policies and Activities : COM (96) 67 final of 21 February 1996. Communication from the Commission. 24 p.

7. Jayachandran S. 2015. The Roots of Gender Inequality in Developing Countries. Annual Review of Economics, Vol. 7, pp. 63-88. https://doi.org/10.1146/annurev-economics-080614-115404

8. Kabeer N. 2003. Gender Mainstreaming in Poverty Eradication and the Millennium Development Goals: A Handbook for Policy Makers and Other Stakeholders. Commonwelth Secretariat, London. https://doi.org/10.14217/9781848598133-en

9. Kleven H., Landais C. 2017. Gender Inequality and Economic Development: Fertility, Education, and Norms. Special Issue on Inequality, Vol. 84, Is. 334, pp. 180-209. https://doi.org/10.1111/ecca.12230

10. Kossek E., Su R., Wu L. 2017. “Opting Out” or "Pushed Out”? Integrating Perspectives on Women's Career Equality for Gender Inclusion and Interventions. Journal of Management, Vol. 43 (1), pp. 228-254. https://doi.org/10.1177/0149206316671582

11. Lombardo E., Meie P., Verlo M. 2017. Policymaking from a Gender+ Equality Perspective. Journal of Women, Politics \& Policy, Vol. 38, Iss. 1, pp. 1-19. https://doi.org/10.1080/1554477X.2016.1198206

12. Majurin, E. 2010. How cooperatives work for working women in Africa: Promising Practices, ILO, Geneva.

13. Martin P. 2004. Gender As Social Institution. Social Forces, Vol. 82 (4), pp. 1249-1273. https://doi.org/10.1353/sof.2004.0081

14. Matysiak I. 2015. The feminization of governance in rural communities in Poland: the case of village representatives (soltys). Gender, Place \& Culture: A Journal of Feminist Geography, Vol. 22 (5), pp. $700-716$. https://doi.org/10.1080/0966369X.2013.879104

15. McVay L. 2013. Rural Women in Leadership: Positive Factors in Leadership Development, Spring Arbor University, Arbor. https://doi.org/10.1079/9781780641607.0000

16. Morse, S., McNamara, N. 2013. Sustainable livelihood approach: a critique of theory and practice, Springer, Berlin. https://doi.org/10.1007/978-94-007-6268-8

17. Nemes G., Fazekas Z. 2002. Integrating Rural Women - EU policies and the evolution rural development - The New Challenge of Women's Role in Rural Europe Available at http://www.policy.hu/nemes/publikaciok/integrated\%20rural\%20women.html 
(accessed on 17/02/2013).

18. Oedl-Wieser T. 2015. Gender equality: a core dimension in Rural Development Programmes in Austria? Gender, Place \& Culture: A Journal of Feminist Geography, Vol. 22 (5), pp. 685-699. https://doi.org/10.1080/0966369X.2013.879103

19. Okoń-Horodyńska E. 2015. From innovation to innovative gender. Statistical profiles of women's and men's status in the economy, science and society, Jagiellonian University Press, Krakow.

20. Permanyer I. 2013. A Critical Assessment of the UNDP's Gender Inequality Index. Feminist Economics, Vol. 19, Iss. 2, pp. 1-32. https://doi.org/10.1080/13545701.2013.769687

21. Aufhauser E., Herzog S., Hinterleitner V. et al. 2003. Principles for a "Gender-sensitive Regional Development", Division IV/4 for Co-ordination of Regional Planning and Regional Policies, Vienna.

22. Prugl E. 2011. Transforming Masculine Rule: Agriculture and Rural Development in the European Union. University of Michigan Press, Michigan https://doi.org/10.3998/mpub.2146717

23. Sen, A. 1990. Gender and Cooperative conflicts. Persistent Inequalities: Women and World Development / ed. by I. Tinker, Oxford University Press, Oxford, pp. 123-149.

24. Shortall S. 2015. Gender mainstreaming and the Common Agricultural Policy. Gender, Place \& Culture: A Journal of Feminist Geography, Vol. 22, Iss. 5, pp. 717-730. https://doi.org/10.1080/0966369X.2014.939147

25. Sustainable rural systems. Sustainable agriculture and rural communities 2008 / ed. by G. Robinson. Farnham : Ashgate. 214 p.

26. Tavira N., Tapia F. 2008. The emergence of the relation between rural development and gender. UAEMex 48, pp. $203-234$.

27. Thébaud S. 2015. Business as Plan B. Institutional Foundations of Gender Inequality in Entrepreneurship across 24 Industrialized Countries. Administrative Science Quaterly, Vol. 60, Iss. 4, pp.671-711. https://doi.org/10.1177/0001839215591627

28. Wodon Q. 2018. What Is the Cost of Gender Inequality in Lost Earnings? Global Estimates Based on the Changing Wealth of Nations. Mimeo, The World Bank, Washington, DC. 